\title{
Budesonide-hydroxypropyl- $\beta$-cyclodextrin inclusion complex in binary poloxamer $407 / 403$ system for ulcerative colitis treatment: A physico-chemical study from micelles to hydrogels
}

\author{
Alessandra Cristina Santos Akkari a , Estefânia Vangelie Ramos Campos ${ }^{\mathrm{b}}$, \\ Artur Franz Keppler ${ }^{a}$, Leonardo Fernandes Fraceto ${ }^{b}$, Eneida de Paula ${ }^{c}$, \\ Giovana Radomille Tófoli ${ }^{\mathrm{d}}$, Daniele Ribeiro de Araujo ${ }^{\mathrm{a}, *}$ \\ ${ }^{a}$ Human and Natural Sciences Center, Federal University of ABC, Santo André, SP, Brazil \\ b Department of Enviroment Engineering, State University “Júlio de Mesquita Filho", Sorocaba, SP, Brazil

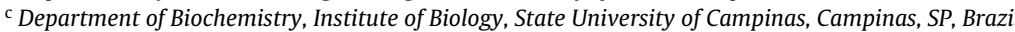 \\ d Faculty of Dentistry São Leopoldo Mandic, Campinas, SP, Brazil
}

\section{A R T I C L E I N F O}

\section{Article history:}

Received 12 August 2015

Received in revised form

18 November 2015

Accepted 25 November 2015

Available online 30 November 2015

\section{Keywords:}

Budesonide

Cyclodextrin

Poloxamer

Micelle

Hydrogel

Ulcerative colitis

Polyrotaxane

\begin{abstract}
A B S T R A C T
Budesonide (BUD) is a glucocorticoid widely used for the treatment of ulcerative colitis. In this work, we propose the study of the system BUD-HP- $\beta-C D$ inclusion complex incorporated into PL 407 and PL407-PL403 thermoreversible hydrogels, considering physico-chemical and pharmaceutical aspects. Complexation between BUD and HP- $\beta-C D$ was confirmed by phase solubility studies ( $1: 1$ stoichiometry, $\left.K c=8662.8 \mathrm{M}^{-1}\right)$, DSC, FTIR and microscopy analyzes. BUD solubility in simulated upper and lower colon fluids was improved in a dependence of HP- $\beta-C D$ and PL 407 or PL407-PL403 association. Micellar hydrodynamic diameter studies showed the interaction between HP- $\beta-C D$ and PL blocks, as well as the reorganization of the micellar system in the presence of BUD and its inclusion complex. Micellization temperature $\left(T_{\mathrm{m}}\right)$ was not shifted, but sol-gel phase transition studies showed that in the presence of BUD, HP- $\beta-C D$ or BUD:HP- $\beta-C D$ complex, the association PL407-PL403 favored the gel formation close to the physiological temperature. Physico-chemical and in vitro release assays studies revealed no competitive displacement of BUD from the HP- $\beta$-CD cavity evoked by PL407 or PL407-PL403 addition. These findings point out the BUD-HP- $\beta$-CD in PL-based hydrogels as strategies for future investigations on development of new pharmaceutical formulations for the treatment of ulcerative colitis.
\end{abstract}

(c) 2015 Elsevier B.V. All rights reserved.

\section{Introduction}

Ulcerative Colitis (UC) is a chronic inflammatory disease that affects the mucosa and submucosa of the large intestine, which may extend over the entire colon [1]. The pharmacological treatment of UC is based on the use of corticoids drugs, in particular budesonide (BUD). BUD is a glucocorticoid with predominant local anti-inflammatory activity and low systemic absorption (approximately 35\%). It reduces the inherent adverse effects of systemic corticosteroids (such as suppression of the hypothalamic-pituitaryadrenal axis), making this drug a favorable therapeutic option

* Corresponding author at: Centro de Ciências Naturais e Humanas, Universidade Federal do ABC, UFABC. Av dos Estados, 5001. Bairro Bangú. Bloco A, Torre 3, Sala 623-3, Santo André, SP CEP 09210-580, Brazil.

E-mail addresses: daniele.araujo@ufabc.edu.br, draraujo2008@gmail.com, draraujo2012@gmail.com (D.R. de Araujo). for the treatment of inflammatory bowel diseases [2]. Despite its extensive clinical use, BUD presents low aqueous solubility [3] and extensive first-pass biotransformation, which reduces its effectiveness when administered orally or even by inhalers [4].

The available formulations containing BUD for the treatment of UC are provided in capsules for enteric release or as enema. However, the capsules have intrinsic limitations related to the BUD low bioavailability and the enema formulation causes loss during the administration and discomfort to the patient because of the large volume and low viscosity of the formulation. Then, the development of drug-delivery systems is of great interest to reduce the adverse effects and improve the patient compliance [2].

The complexation of drugs with cyclodextrins (CD) has been extensively studied for different molecules being intended for administration by different routes [5] due to their chemical stability and biocompatibility [6]. Specifically, hydroxypropylbeta-cyclodextrin (HP- $\beta-C D$ ) has the advantage of its high aqueous 
A
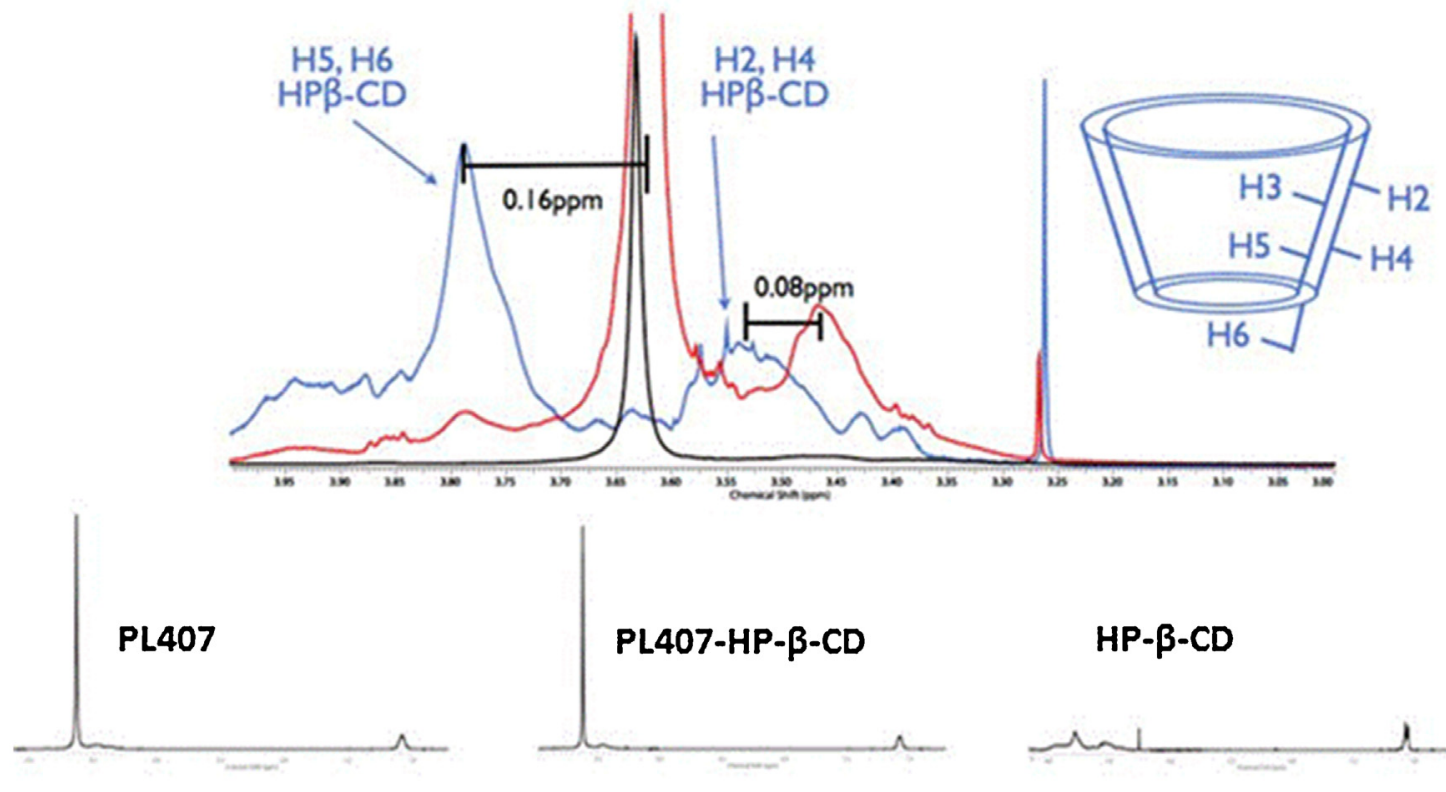

HP- $\beta-C D$
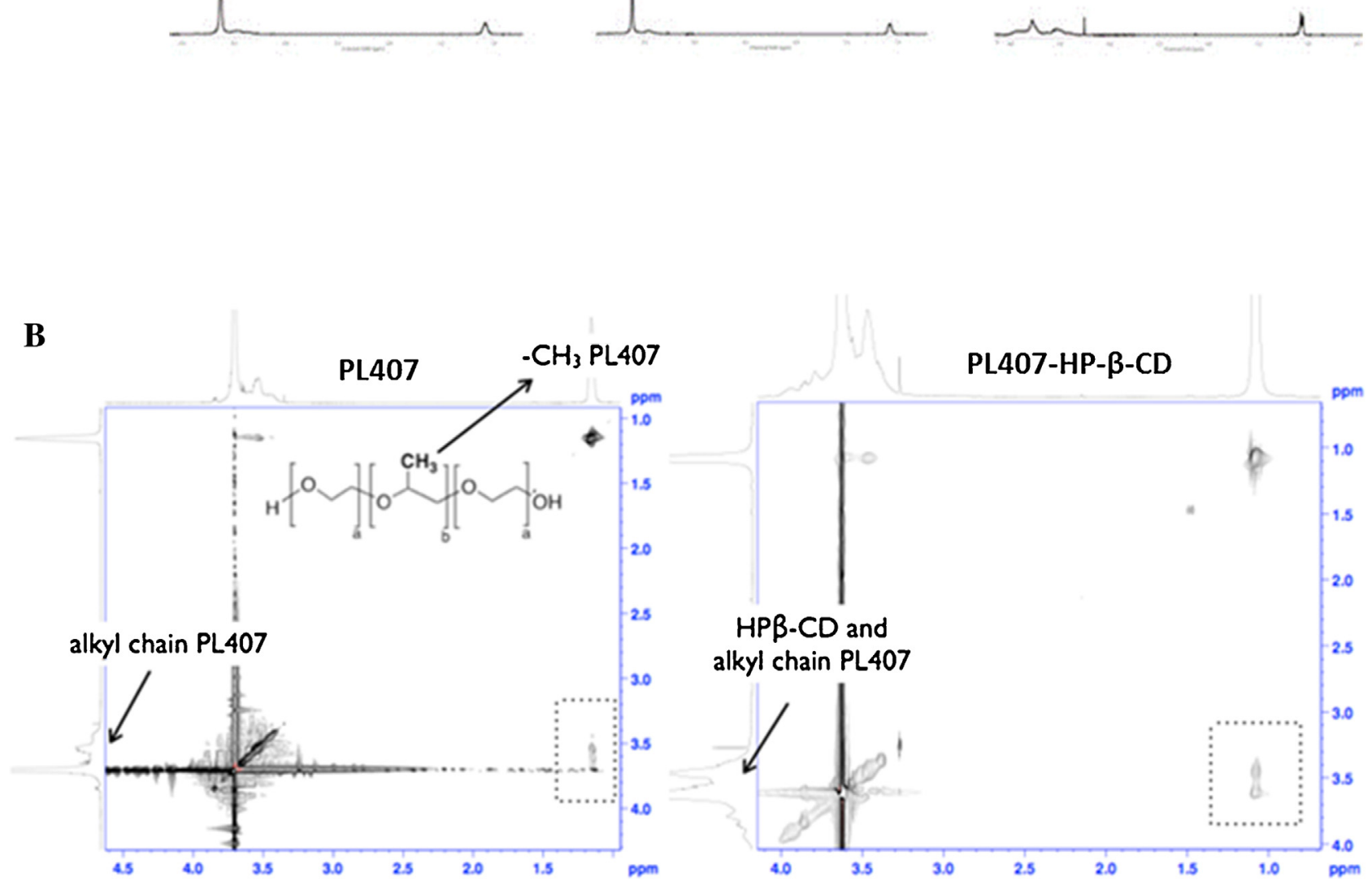

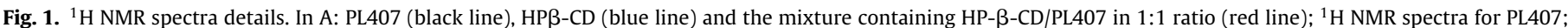

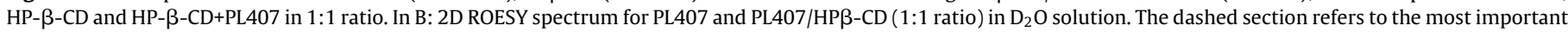
ROESY interaction. (For interpretation of the references to colour in this figure legend, the reader is referred to the web version of this article).

solubility and low systemic toxicity, considered by FDA inert pharmaceutical excipients [7]. However, inclusion complexes present relatively fast uptake by blood stream. For maintaining the formulation at the site of administration, in-situ forming hydrogels have been proposed as strategies for incorporation of different molecules, since thermosensitive hydrogels are liquid before administration and undergo a phase transition forming a transparent gel at physiological temperature.

In order to increase the BUD aqueous solubility and also its permanence at the colonic region, we propose the incorporation of BUD-HP- $\beta-C D$ inclusion complex into poloxamer (PL)-based hydrogels with different hydrophilic lipophilic balances (HLB), such as PL 407 and PL 403 with HLB values of 22 and 8 [8]. We studied physicochemical aspects such as drug solubility, hydrodynamic diameter, the interaction between PL and HP- $\beta-C D$, thermodynamics aspects of micellization, sol-gel transition phase, and, finally, morphology analysis, investigating the influence of the PL composition and the addition of the BUD, or its inclusion complex BUD-HP- $\beta-C D$, on micelles and hydrogel structure in order to develop new pharmaceutical formulations for the treatment of ulcerative colitis. 

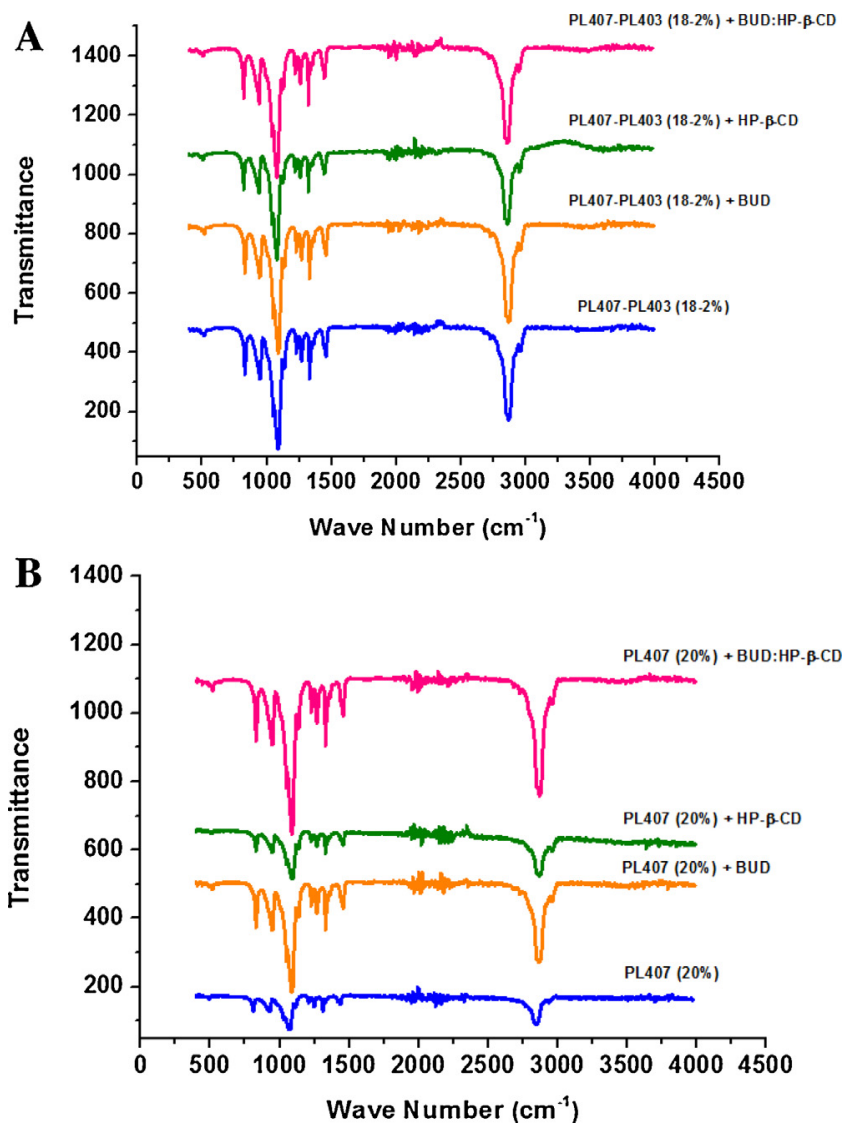

Fig. 2. Infrared spectra for (A) PL407-PL403 (18-2\%) and (B) PL 407 (20\%) systems before and after incorporation of budesonide (BUD), hydroxypropyl- $\beta$-cyclodextrin (HP- $\beta-C D)$ and inclusion complex (BUD: HP- $\beta-C D .1: 1$ molar ratio).

\section{Materials and methods}

\subsection{Chemicals}

Poloxamer 407 (Pluronic ${ }^{\circledR}$ F-127), Poloxamer 403 (Pluronic ${ }^{\circledR}$ P123), 2-Hydroxypropyl- $\beta$-cyclodextrin $(\mathrm{HP}-\beta-\mathrm{CD})$ and budesonide (BUD) were purchased from Sigma-Aldrich, MO, USA. All other chemicals and solvents were of analytical grade. Simulated upper colonic fluid (SUCF) was prepared with sodium chloride (17 mM), acetic acid $(70 \mathrm{mM})$ and propionic acid $(30 \mathrm{mM})$ while simulated lower colonic fluid (SLCF) was prepared with sodium chloride
(17 $\mathrm{mM})$, acetic acid $(25 \mathrm{mM})$ and propionic acid $(10 \mathrm{mM})$. The $\mathrm{pH}$ was adjusted to 6.2 (SUCF) and 7.0 (SLCF) [9].

\subsection{Preparation of BUD:HP- $\beta-C D$ inclusion complex and PL-based hydrogels}

BUD:HP- $\beta-C D$ inclusion complexes were obtained by mixing HP- $\beta-C D$ and BUD in water, at 1:1 drug:CD molar ratio. The samples were homogenized for $24 \mathrm{~h}$, at $25^{\circ} \mathrm{C}$, lyophilized and stored at $-20^{\circ} \mathrm{C}$ until use [5]. Phase solubility assays were described into the Supporting information Section.

Hydrogels composed of PL407 (18 and 20\% w/w) isolated or in association with PL403 (18/2\% PL407/PL403\% w/w) were prepared according to the cold method [10]. The BUD-PL hydrogels were obtained by drug dispersion $\left(500 \mu \mathrm{g} \mathrm{mL}^{-1}\right)$ into the polymer solution and kept at $4{ }^{\circ} \mathrm{C}$ under stirring $(100 \mathrm{rpm})$ for at least $6 \mathrm{~h}$. For inclusion complex-PL hydrogels, BUD:HP- $\beta-C D$ (molar ratio $1: 1$ ) was added to the different PL-formulations at the same final BUD concentration as the BUD-PL system. HP- $\beta-C D$ concentration in PL-hydrogels was considered in relation to the inclusion complex.

\subsection{BUD solubility studies in colonic fluids}

Solubility tests were performed adding constant concentrations for BUD $(0.25 \mathrm{mM})$ and HP- $\beta-C D(0.25 \mathrm{mM})$ to PL 407 or PL407PL403 (0.125 mM to $1 \mathrm{mM}$ ) solutions, prepared in upper and lower colonic fluids. Samples were shaking at room temperature for $24 \mathrm{~h}$, filtered (polycarbonate membrane with $0.22 \mu \mathrm{m}$ pore) and BUD concentration determined.

\subsection{Nuclear magnetic resonance (NMR)}

One-dimensional ${ }^{1} \mathrm{H}-\mathrm{NMR}$ spectra were recorded at $298 \mathrm{~K}$ on a Bruker Avance III at a frequency of $300.13 \mathrm{MHz}$ in $\mathrm{D}_{2} \mathrm{O}$. Typical acquisition parameters consisted of $64 \mathrm{~K}$ points covering a sweep width of $4201 \mathrm{~Hz}$, an acquisition time of $7.8 \mathrm{~s}$ and a relaxation delay of $1 \mathrm{~s}$. Chemical shifts were reported in parts per million (ppm) and the spectra were referenced to the proton resonance of the residual solvent $\left(\mathrm{H}_{2} \mathrm{O}\right.$ and $\left.\mathrm{HOD}\right)$ at $4.7 \mathrm{ppm}$. Rotating-frame Overhauser Effect Spectroscopy (ROESY) spectra were acquired in the phase sensitive mode. Each spectrum consisted of a matrix of $4 \mathrm{~K}$ (F2) by $256 \mathrm{~K}$ (F1) points, covering a spectral width of $4201 \mathrm{~Hz}$. The ROESY mixing time was $300 \mathrm{~ms}$. Solutions of HP- $\beta-C D(8 \mathrm{mM})$, PL407 ( $8 \mathrm{mM})$, PL407/PL403 (10:1 ratio, $8 \mathrm{mM})$ and the mixture of polymer/inclusion complex (1:1 molar ratio, $8 \mathrm{mM})$ were pre-

Table 1

Budesonide aqueous solubility on simulated upper (SUCF. pH 6.2) and lower colon fluids (SLCF. pH 7.0). in the presence or absence of hydroxypropyl- $\beta$-cyclodextrin.

\begin{tabular}{|c|c|c|c|c|c|}
\hline & \multirow[t]{2}{*}{ Molar ratio (BUD:HP $\beta-C D: P L)$} & \multicolumn{2}{|l|}{$\mathrm{BUD}(\mathrm{mM})$} & \multicolumn{2}{|c|}{ Solubility increment (\%) } \\
\hline & & PL407 & PL407/PL403 & PL407 & PL407/PL403 \\
\hline \multirow{7}{*}{$\begin{array}{l}\text { Simulated upper } \\
\text { colonic fluid (SUCF) }\end{array}$} & $1: 0: 0$ & $0.10 \pm 0.004$ & $0.10 \pm 0.004$ & - & - \\
\hline & $1: 1: 0$ & $0.12 \pm 0.009$ & $0.12 \pm 0.009$ & $19 \%$ & $19 \%$ \\
\hline & $1: 1: 0.5$ & $0.11 \pm 0.012$ & $0.13 \pm 0.007$ & $9 \%$ & $32 \%$ \\
\hline & $1: 1: 1$ & $0.11 \pm 0.001$ & $0.15 \pm 0.005$ & $4 \%$ & $55 \%$ \\
\hline & $1: 1: 1.5$ & $0.13 \pm 0.004$ & $0.17 \pm 0.013$ & $35 \%$ & $68 \%$ \\
\hline & $1: 1: 2$ & $0.15 \pm 0.011$ & $0.16 \pm 0.010$ & $52 \%$ & $63 \%$ \\
\hline & $1: 1: 4$ & $0.16 \pm 0.010$ & $0.21 \pm 0.011$ & $63 \%$ & $114 \%$ \\
\hline \multirow{7}{*}{$\begin{array}{l}\text { Simulated lower } \\
\text { colonic fluid (SLCF) }\end{array}$} & $1: 0: 0$ & $0.08 \pm 0.007$ & $0.08 \pm 0.007$ & - & - \\
\hline & $1: 1: 0$ & $0.10 \pm 0.013$ & $0.10 \pm 0.013$ & $28 \%$ & $28 \%$ \\
\hline & $1: 1: 0.5$ & $0.08 \pm 0.004$ & $0.13 \pm 0.002$ & $9 \%$ & $66 \%$ \\
\hline & $1: 1: 1$ & $0.11 \pm 0.006$ & $0.13 \pm 0.004$ & $46 \%$ & $69 \%$ \\
\hline & $1: 1: 1.5$ & $0.12 \pm 0.009$ & $0.15 \pm 0.001$ & $54 \%$ & $93 \%$ \\
\hline & $1: 1: 2$ & $0.13 \pm 0.005$ & $0.15 \pm 0.001$ & $69 \%$ & $102 \%$ \\
\hline & $1: 1: 4$ & $0.14 \pm 0.007$ & $0.21 \pm 0.006$ & $80 \%$ & $182 \%$ \\
\hline
\end{tabular}


Table 2

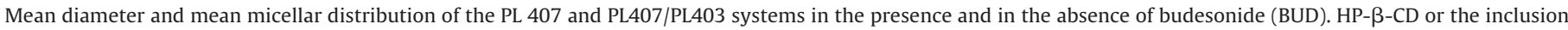
complex BUD:HP- $\beta-\mathrm{CD}$ at temperatures of $25^{\circ} \mathrm{C}$ and $37^{\circ} \mathrm{C}$.

\begin{tabular}{|c|c|c|c|c|}
\hline \multirow[b]{2}{*}{ Formulation } & \multicolumn{2}{|l|}{$25^{\circ} \mathrm{C}$} & \multicolumn{2}{|l|}{$37^{\circ} \mathrm{C}$} \\
\hline & Hydrodynamic diameter (nm) & Average distribution (\%) & Hydrodynamic diameter (nm) & Average distribution (\%) \\
\hline PL 407 & $\begin{array}{r}52.9 \pm 0.8 \\
4.9 \pm 0.1\end{array}$ & $\begin{array}{l}76.3 \pm 1.4 \\
12.6 \pm 0.7\end{array}$ & $\begin{array}{l}23.7 \pm 1.6 \\
-\end{array}$ & $\begin{array}{l}100.0 \pm 0.0 \\
-\end{array}$ \\
\hline PL 407/PL 403 & $\begin{aligned} 52.0 & \pm 2.0 \\
5.7 & \pm 0.5\end{aligned}$ & $\begin{array}{r}91.0 \pm 0.6 \\
9.0 \pm 0.6\end{array}$ & $\begin{array}{l}25.0 \pm 0.4 \\
-\end{array}$ & $\begin{array}{l}100.0 \pm 0.0 \\
-\end{array}$ \\
\hline PL 407-HP- $\beta-C D$ & $\begin{aligned} 62.6 & \pm 3.8 \\
5.0 & \pm 0.6\end{aligned}$ & $\begin{array}{l}86.9 \pm 1.6 \\
11.9 \pm 1.6\end{array}$ & $\begin{aligned} 26.9 & \pm 1.0 \\
1.7 & \pm 3.0\end{aligned}$ & $\begin{aligned} 99.1 & \pm 1.4 \\
0.8 & \pm 1.4\end{aligned}$ \\
\hline $\begin{array}{l}\text { PL } 407 / \mathrm{PL} \\
403-\mathrm{HP}-\beta-\mathrm{CD}\end{array}$ & $\begin{aligned} 54.3 & \pm 2.2 \\
5.2 & \pm 0.3\end{aligned}$ & $\begin{array}{r}90.8 \pm 1.9 \\
8.2 \pm 0.3\end{array}$ & $\begin{array}{r}26.2 \pm 1.5 \\
2.0 \pm 3.5\end{array}$ & $\begin{array}{r}98.9 \pm 1.9 \\
1.1 \pm 1.9\end{array}$ \\
\hline PL 407-BUD & $\begin{aligned} 54.3 & \pm 2.1 \\
5.0 & \pm 0.6\end{aligned}$ & $\begin{array}{l}86.2 \pm 1.0 \\
13.1 \pm 0.9\end{array}$ & $\begin{array}{r}26.6 \pm 1.4 \\
2.1 \pm 3.7\end{array}$ & $\begin{aligned} 95.0 & \pm 8.7 \\
5.0 & \pm 8.7\end{aligned}$ \\
\hline PL 407/PL 403-BUD & $\begin{aligned} 54.1 & \pm 1.9 \\
5.3 & \pm 0.3\end{aligned}$ & $\begin{array}{r}90.9 \pm 0.6 \\
9.1 \pm 0.6\end{array}$ & $\begin{array}{r}24.1 \pm 0.6 \\
1.4 \pm 2.4\end{array}$ & $\begin{array}{r}98.7 \pm 2.3 \\
1.3 \pm 2.3\end{array}$ \\
\hline PL 407-BUD:HP- $\beta-C D$ & $\begin{aligned} 95.0 & \pm 8.1 \\
5.6 & \pm 0.6\end{aligned}$ & $\begin{array}{r}90.7 \pm 0.8 \\
8.4 \pm 0.4\end{array}$ & $\begin{array}{l}22.5 \pm 1.5 \\
-\end{array}$ & $\begin{array}{l}100.0 \pm 0.0 \\
-\end{array}$ \\
\hline $\begin{array}{l}\text { PL407/PL403-BUD:HP- } \\
\beta-C D\end{array}$ & $\begin{aligned} 59.0 & \pm 2.5 \\
5.2 & \pm 0.3\end{aligned}$ & $\begin{array}{l}89.6 \pm 0.1 \\
10.0 \pm 0.7\end{array}$ & $\begin{array}{l}35.0 \pm 7.2 \\
-\end{array}$ & $\begin{array}{l}100.0 \pm 0.0 \\
-\end{array}$ \\
\hline
\end{tabular}

Note: Data expressed as mean $\pm \mathrm{SD}(n=6$ /formulation).

Table 3

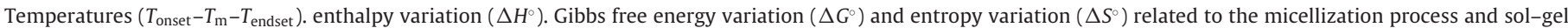
transition temperature of the polymeric systems 20 and 18\% PL407 and 18/2\% PL407/PL403 ( $n=6 /$ formulation).

\begin{tabular}{|c|c|c|c|c|c|c|c|c|}
\hline Formulation & Concentration (\%) & $T_{\text {onset }}\left({ }^{\circ} \mathrm{C}\right)$ & $T_{\mathrm{m}}\left({ }^{\circ} \mathrm{C}\right)$ & $T_{\text {endset }}\left({ }^{\circ} \mathrm{C}\right)$ & $\Delta H^{\circ}\left(\mathrm{kJ} \mathrm{mol}^{-1}\right)$ & $\Delta G^{\circ}\left(\mathrm{kJ} \mathrm{mol}^{-1}\right)$ & $\Delta S^{\circ}\left(\mathrm{kJ} \mathrm{mol} \mathrm{K}^{-1}\right)$ & $\mathrm{T}_{\text {sol/gel }}\left({ }^{\circ} \mathrm{C}\right)$ \\
\hline PL 407 & 18 & 14.8 & 17.8 & 25.4 & 219.9 & -26.9 & 0.85 & $>70$ \\
\hline PL 407-HP- $\beta-C D$ & & 14.8 & 21.4 & 41.9 & 387.2 & -27.3 & 2.20 & $>70$ \\
\hline PL 407-BUD & & 14.0 & 18.3 & 28.5 & 227.0 & -27.0 & 0.88 & $>70$ \\
\hline PL 407-BUD:HP- $\beta-C D$ & & 13.3 & 17.5 & 30.7 & 310.1 & -26.9 & 1.16 & $>70$ \\
\hline PL 407 & 20 & 14.5 & 18.2 & 27.9 & 210.5 & -26.7 & 0.81 & $35.8 \pm 0.4$ \\
\hline PL 407-HP- $\beta-C D$ & & 14.5 & 18.2 & 27.2 & 242.6 & -26.7 & 0.92 & $37.0 \pm 0.5$ \\
\hline PL 407-BUD & & 13.5 & 17.5 & 25.9 & 214.7 & -26.7 & 0.80 & $35.0 \pm 0.1$ \\
\hline PL 407-BUD:HP- $\beta-C D$ & & 14.3 & 18.8 & 30.9 & 197.4 & -26.8 & 0.77 & $34.0 \pm 0.1$ \\
\hline PL 407-PL403 & $18: 2$ & 12.9 & 17.4 & 26.7 & 178.9 & -26.4 & 0.71 & $>70$ \\
\hline PL 407-PL403-HP- $\beta-C D$ & & 13.1 & 17.6 & 25.9 & 216.5 & -26.4 & 0.84 & $33.0 \pm 0.2$ \\
\hline PL 407-PL403-BUD & & 12.6 & 17.2 & 26.5 & 218.9 & -26.4 & 0.85 & $34.2 \pm 0.4$ \\
\hline PL 407-PL403-BUD:HP- $\beta-C D$ & & 12.5 & 17.6 & 29.3 & 112.9 & -26.4 & 0.50 & $35.0 \pm 0.2$ \\
\hline
\end{tabular}

$T_{\text {onset }}$ :temperature at the start of the micellization process.

$T_{\mathrm{m}}$ :micellization temperature.

$T_{\text {endset }}$ :temperature at the end of the micellization process.

pared and mixed prior to perform the one-dimensional ${ }^{1} \mathrm{H}$ NMR and ROESY spectra.

2.5. PL-based systems containing $H P-\beta-C D, B U D$ or

$B U D-H P-\beta-C D$ : physicochemical characterization

\subsubsection{Micellar hydrodynamic diameter and average size} distribution

Micellar hydrodynamic diameter, polydispersion and average distribution were determined by Light scattering, using a NanoSeries ZS90 (Malvern ${ }^{\circledR}$ Instruments) particle analyzer (at $173^{\circ}$ ). PL407 and PL407/PL403 solutions (4\% w/v) were previously prepared, filtered (polycarbonate membrane, $0.22 \mu \mathrm{m}$ pore) and analyzed. All measurements were carried out at least five times, at both temperatures 25 and $37^{\circ} \mathrm{C}$.

\subsubsection{Differential scanning calorimetry (DSC) studies: inclusion} complex, micellization and thermal reversibility characterization

Samples of the hydrogels (18\% PL407, 20\% PL407 and 18/2\% PL407/PL403) were analyzed in the presence or absence of BUD, HP- $\beta-C D$ or BUD:HP- $\beta-C D$ inclusion complex (molar ratio $1: 1$ ), according to three heating-cooling cycles $\left(5^{\circ} \mathrm{C} / \mathrm{min}\right)$ : cycle 1 - heat- ing from $0^{\circ} \mathrm{C}$ to $50^{\circ} \mathrm{C}$; cycle 2 - cooling from $50^{\circ} \mathrm{C}$ to $0^{\circ} \mathrm{C}$; and cycle 3- heating from $0^{\circ} \mathrm{C}$ to $50^{\circ} \mathrm{C}$. All analyses were performed in triplicate and thermograms presented as heat flux (cal/gs) as a function of temperature $\left({ }^{\circ} \mathrm{C}\right)$.

\subsection{Fourier transformed infrared (FTIR) analyses}

Fourier transformed infrared (FTIR) analyses were performed using a spectrometer with wavenumber range from 4500 to $500 \mathrm{~cm}^{-1}$, the incidence angle was $45^{\circ}$, and 100 scans were collected for each sample, at a resolution of $0.25 \mathrm{~cm}^{-1}$.

\subsubsection{Sol-gel phase transition temperature}

The tube inversion method was performed using vials containing $1 \mathrm{~g}$ of the different samples of hydrogels, maintained in a water bath at $0^{\circ} \mathrm{C}$ for $20 \mathrm{~min}$ for the thermal balance. Temperature was gradually raised $\left(1^{\circ} \mathrm{C} / 5 \mathrm{~min}\right)$ from $0{ }^{\circ} \mathrm{C}$ to $65^{\circ} \mathrm{C}$. For each thermal variation, samples were removed from the bath, visually analyzed and classified according to: (1) liquid-complete inversion of the sample; (2) viscous liquid or soft gel-slow inversion of the sample; (3) and hard-gel-the sample remains completely positioned at the bottom of the tube. 
Table 4

Release parameters for hydrogels formulations according to different mathematic models.

\begin{tabular}{|c|c|c|c|c|c|c|c|c|c|}
\hline \multirow[t]{2}{*}{ SUCF (pH 6.2) } & \multicolumn{2}{|c|}{ Zero-order } & \multicolumn{2}{|c|}{ Higuchi } & \multicolumn{2}{|c|}{ Hixson-Crowel } & \multicolumn{3}{|c|}{ Korsmeyer-Peppas } \\
\hline & $\overline{R^{2}}$ & $\overline{K_{0}\left(\% \cdot \mathrm{h}^{-1}\right)}$ & $\overline{R^{2}}$ & $\overline{K_{0}\left(\% \cdot \mathrm{h}^{-1 / 2}\right)}$ & $\overline{R^{2}}$ & $\overline{K_{\mathrm{HC}}\left(\% \cdot \mathrm{h}^{-1 / 3}\right)}$ & $\overline{R^{2}}$ & $n$ & $K_{\mathrm{KP}}\left(\% \cdot \mathrm{h}^{-\mathrm{n}}\right)$ \\
\hline $\mathrm{F} 1$ & 0.680 & 0.94 & 0.979 & 4.13 & 0.711 & 0.02 & 0.910 & 0.08 & 8.91 \\
\hline $\mathrm{F} 2$ & 0.696 & 1.33 & 0.964 & 3.15 & 0.731 & 0.03 & 0.933 & 0.07 & 7.95 \\
\hline F3 & 0.990 & 0.95 & 0.937 & 3.70 & 0.917 & 0.07 & 0.973 & 0.09 & 4.51 \\
\hline $\mathrm{F} 4$ & 0.606 & 0.49 & 0.947 & 1.78 & 0.969 & 0.04 & 0.920 & 0.04 & 12.19 \\
\hline F5 & 0.913 & 1.34 & 0.937 & 5.88 & 0.919 & 0.04 & 0.990 & 0.07 & 13.72 \\
\hline F6 & 0.741 & 0.68 & 0.984 & 3.28 & 0.772 & 0.01 & 0.978 & 0.05 & 12.43 \\
\hline \multirow[t]{2}{*}{$\operatorname{SLCF}(\mathrm{pH} 7.0)$} & \multicolumn{2}{|c|}{ Zero-order } & \multicolumn{2}{|c|}{ Higuchi } & \multicolumn{2}{|c|}{ Hixson-Crowel } & \multicolumn{3}{|c|}{ Korsmeyer-Peppas } \\
\hline & $\overline{R^{2}}$ & $K_{0}\left(\% \cdot \mathrm{h}^{-1}\right)$ & $\overline{R^{2}}$ & $\overline{K_{0}\left(\% \cdot \mathrm{h}^{-1 / 2}\right)}$ & $\overline{R^{2}}$ & $K_{\mathrm{HC}}\left(\% \cdot \mathrm{h}^{-1 / 3}\right)$ & $\overline{R^{2}}$ & $n$ & $K_{\mathrm{KP}}\left(\% \cdot \mathrm{h}^{-\mathrm{n}}\right)$ \\
\hline F1 & 0.728 & 1.10 & 0.976 & 3.99 & 0.746 & 0.02 & 0.911 & 0.08 & 8.72 \\
\hline $\mathrm{F} 2$ & 0.602 & 0.41 & 0.979 & 3.14 & 0.635 & 0.01 & 0.909 & 0.07 & 7.78 \\
\hline F3 & 0.883 & 0.73 & 0.966 & 3.56 & 0.953 & 0.06 & 0.974 & 0.08 & 5.89 \\
\hline F4 & 0.792 & 0.31 & 0.914 & 2.09 & 0.913 & 0.03 & 0.875 & 0.05 & 9.14 \\
\hline F5 & 0.965 & 1.28 & 0.930 & 5.59 & 0.917 & 0.03 & 0.990 & 0.07 & 14.34 \\
\hline F6 & 0.703 & 0.76 & 0.986 & 3.85 & 0.729 & 0.02 & 0.948 & 0.06 & 11.70 \\
\hline
\end{tabular}

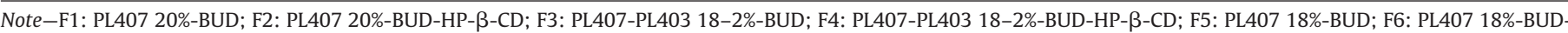

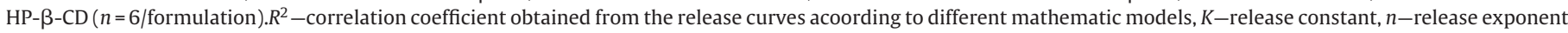
applied to the Korsmeyer-Peppas model. SUCF-Simulated Upper Colonic Fluid; SLCF-Simulated Lower Colonic Fluid.

\subsubsection{Scanning electron microscopy (SEM)}

Morphological features of BUD, HP- $\beta-C D$, physical mixture (BUD + HP- $\beta-C D)$, BUD:HP- $\beta-C D$ inclusion complex (1:1) and PL 407 or PL 407-PL403 formulations were analyzed by Scanning Electron Microscopy (SEM). In order to obtain solid materials, PL hydrogels (containing BUD, HP- $\beta-C D$ and inclusion complex) were placed in a glass slide, forming a thin film and incubated at $40^{\circ} \mathrm{C}$ for $24 \mathrm{~h}$. All samples were examined in a scanning electron microscope with a magnification of 250 times and accelerating voltage of $1 \mathrm{kV}$ [11].

\subsubsection{In vitro release studies}

In vitro release assays were performed using a membraneless model, in order to simulate the contact of the formulations with colonic fluids. A two-compartment system composed of a separate glass cell (donor cell with $0.8 \mathrm{~cm}$ internal diameter and height $2.5 \mathrm{~cm}$ ) was inserted in a receptor compartment and filled with $2 \mathrm{~mL}$ of each formulation. When the temperature inside the donor cell reached $37^{\circ} \mathrm{C}$, the receptor compartment was filled with $20 \mathrm{~mL}$ of SUCF and SLCF under constant magnetic stirring $(350 \mathrm{rpm}$ ). At regular intervals from $30 \mathrm{~min}$. until $48 \mathrm{~h}, 1 \mathrm{~mL}$ of the receptor solution was withdrawn and replaced with fresh fluids. The drug content was analyzed by HPLC (Supporting information) and expressed as release percentage against time.

The in vitro release profiles were analyzed according to the following models:

$Q_{t}=Q_{0}+K_{0} \times t$

$Q_{t}$ is the cumulative amount of drug released at time $t, Q_{0}$ is the initial amount of drug, $K_{0}$ is the zero-order release constant, and $t$ is time;

$Q_{t}=K_{\mathrm{H}} \times t^{1 / 2}$

The rate of drug release is linear as a function of square root of time and the release mechanism follows the Fick's law. $K_{\mathrm{H}}$ is the release coefficient, $Q_{t}$ is the amount of drug released;

$Q_{0}^{1 / 3}-Q^{1 / 3}=K_{\mathrm{HC}} \times t$

$Q_{0}$ is the initial amount of drug, $Q t$ is the cumulative amount of drug released, $K_{\mathrm{HC}}$ is the release constant and $t$ is the time.

$\frac{M_{\mathrm{t}}}{M_{\infty}}=K_{\mathrm{KP}} \times t^{n}$
$M_{\mathrm{t}} / M_{\infty}$ is the fraction of drug released at time $t, K_{\mathrm{KP}}$ is a rate constant and $n$ is the release exponent. An $n$ value of 0.45 represents Fickian diffusion, $0.45<n<0.89$ is anomalous (non-Fickian) diffusion, $n=0.89$ is case-II transport and $n>0.89$ super case-II transport.

\section{Results and discussion}

\subsection{BUD solubility: $H P-\beta-C D$ and PL-mixed systems in simulated colon fluids}

The BUD solubility in the different formulations and the factors that modify the drug solubility were analyzed considering the simulated upper colon fluid (SUCF, pH 6.2) and lower colon fluid (SLCF, $\mathrm{pH} 7.0$ ) in order to observe the possible behavior of the formulations when in contact with different colonic segments (Table 1). It should be noted that the choice of $\mathrm{CD}$ and drug molar ratio constant $(1: 1)$ was due to the results observed for the inclusion complex BUD: HP- $\beta-C D$ at $1: 1$ molar ratio (Supporting information). In general, the presence of HP- $\beta-C D$ and PL improved the BUD solubility. The addition of HP- $\beta-C D$ increased the concentration of solubilized BUD approximately $19(0.12 \mathrm{mM})$ and $28 \%(0.096 \mathrm{mM})$ in SUCF and SLCF, respectively. In addition, an increase on final concentration of PL provided high solubilization percentages, from $80 \%$ up to $182 \%$ for PL407 and PL407-PL403 systems, respectively, when compared to the BUD in SUCF and SLCF.

The increase on aqueous solubility of hydrophobic drugs, in the presence of PL [12-14] and HP- $\beta-C D$ (compared to isolated systems), suggests no or little influence of drug-PL competition for the HP- $\beta-C D$ cavity, highlighting the interest for employing formulations associating both carriers [15]. Those observations are in agreement with our results, since BUD solubility increment obtained for the inclusion complex BUD-HP- $\beta$-CD $1: 1$ is also improved by the high final PL (20\% or $1.58 \mathrm{mM}$ PL407) concentration.

\section{2. $H^{1}$-Nuclear magnetic resonance $\left({ }^{1} H\right.$ NMR $)$ studies: evaluation of PL407 or PL407-PL403-HP- $\beta$-CD interactions}

In this section, we studied the possible interactions between PL407, PL403 and HP- $\beta$-CD. First, a one-dimensional ${ }^{1} \mathrm{H}-\mathrm{NMR}$ spectrum was obtained in order to study the interactions between HP- $\beta-C D$ and PL 407 or PL407-PL403 systems (molar ratio 10:1, the same molar ratio observed for hydrogels formulations)(Fig. 1A) 
A
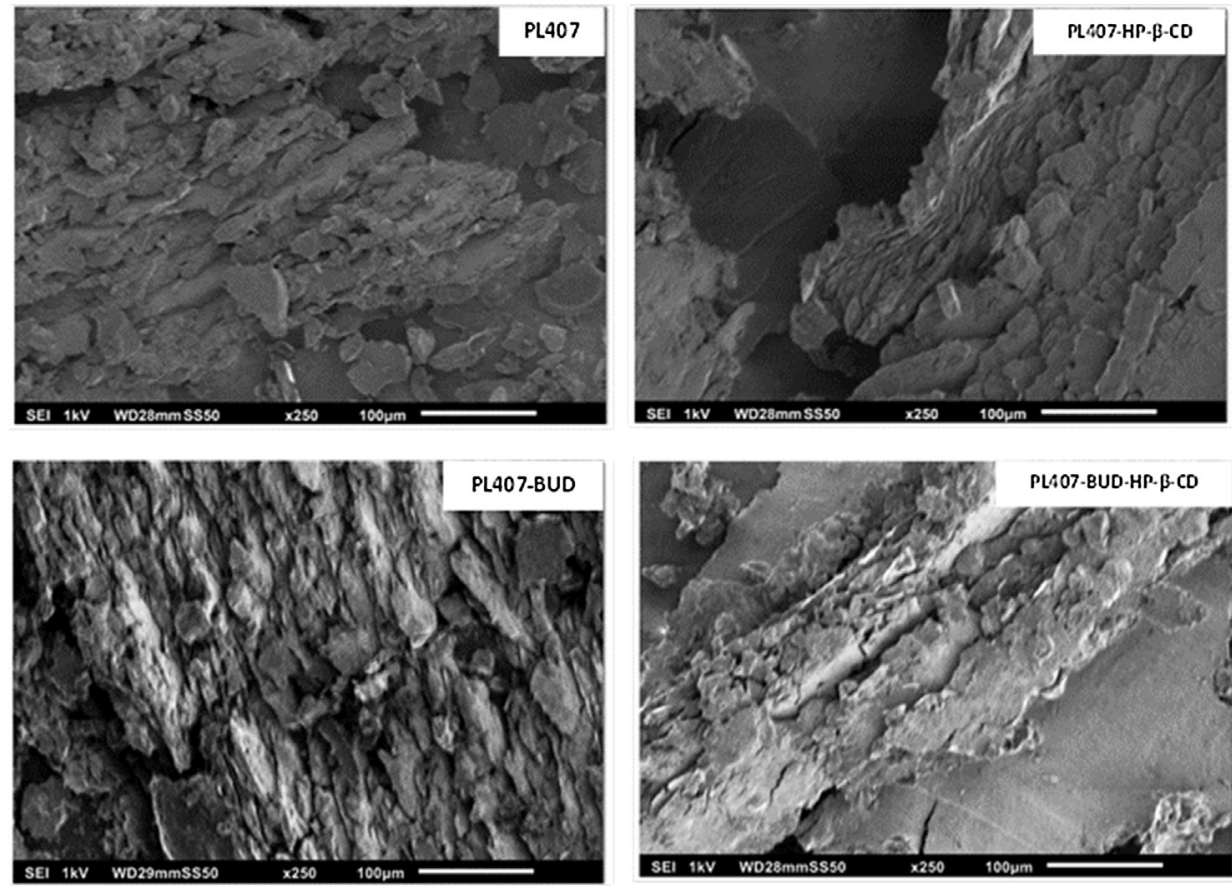

B
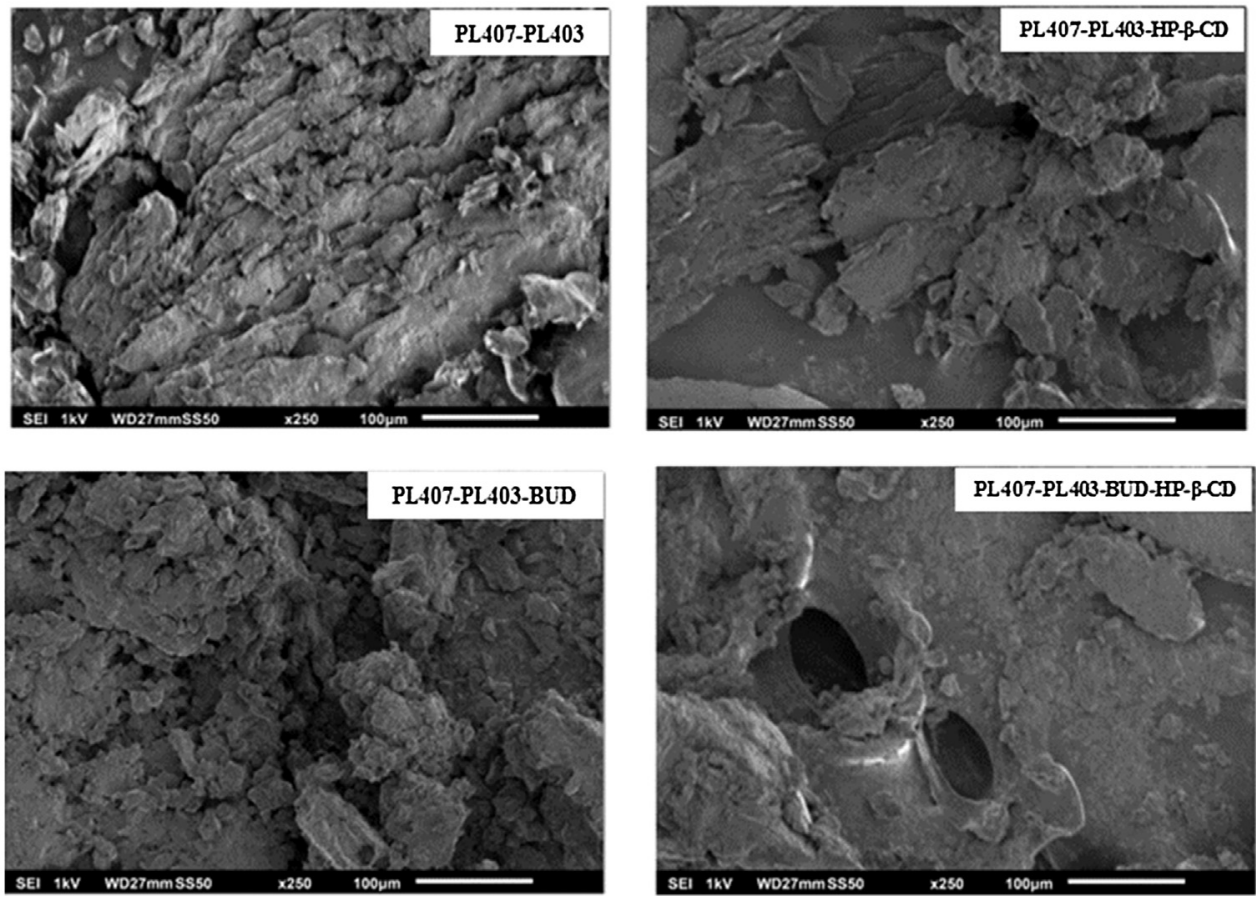

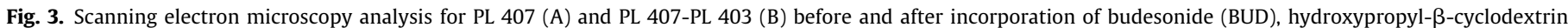
(HP- $\beta-\mathrm{CD})$ and inclusion complex (BUD: HP- $\beta-C D$. 1:1 molar ratio).

The complexation of PL407 with HP- $\beta$-CD was determined by the shielding of the signals of the protons $\mathrm{H}_{3}$ and $\mathrm{H}_{5}$, related to the HP- $\beta-C D$ cavity, indicating that PL interacted with the hydrophobic cavity, resulting in the formation of the complexes PL:HP- $\beta-C D$. However, due to the low proportion of PL403 into the binary system (PL407/PL403; molar ratio 10:1), its lower molecular weight and, especially, the structural similarity between the PL407 and PL403 monomers (both triblock PEO-PPO-PEO), it was no possible to observe the specific interactions between PL403 and HP- $\beta-C D$, using the binary system (PL407-PL403). This observation can be explained by the fact that the presence of hydrophobic PL (PL403) into the formulations prepared contributes to increase the BUD solubility, but not directly to the formation of PL/HP- $\beta-C D$ complexes.

In addition, to characterize the interaction between HP- $\beta-C D$ and PL407, two-dimensional ROESY analyses were carried out for PL 407 and the mixture (1:1 molar ratio) HP- $\beta-C D+$ PL407 (Fig. 2B). For both spectra, an interaction can be seen between the signals at $3.3-3.8 \mathrm{ppm}$ and the signal at $1.0 \mathrm{ppm}$. In special, the spectrum on Fig. 2B, shows the interaction between PL 407 alkyl protons and the methyl group $\left(-\mathrm{CH}_{3}\right)$ of the PL407 PPO blocks, with signals at 3.3-3.8 ppm and $1.0 \mathrm{ppm}$, respectively, which is in line with a previous report [16]. By comparison, on mixed spectrum this interaction was more intense, since the $2 \mathrm{D}$ spectrum is slightly superficial. 
Since the protons of the HP- $\beta-\mathrm{CD}$ cavity resonate at $3.5-3.8 \mathrm{ppm}$ (Fig. 1B), mixing with the signals of the PLalkyl protons, the increase in the intensity of crossed signals can be attributed to the interaction between PL407 methyl group protons with protons localized inside the HP- $\beta-C D$ cavity, indicating the complexation of PL407, in the absence of BUD. In fact, recent studies have demonstrated that, using the signal relatively to the methyl groups directed to the outside of the PPO chain, there is an interaction between the PL407 and the hydrophobic cavity of HP- $\beta-C D$, resulting in supramolecular polypseudorotaxan complexes [15-18].

\subsubsection{PL-based systems containing $H P$ - $\beta$ - $C D, B U D$ or} $B U D-H P-\beta-C D$ inclusion complex: physicochemical characterization

Phase-solubility, DSC, FTIR and MEV analysis for inclusion complex were presented into the Supporting information section.

\subsection{BUD:HP- $\beta C D$-micelle interaction: hydrodynamic diameter and average size distribution}

Table 2 presents the micellar mean hydrodynamic diameter and the average size distribution for the different systems studied (PL407 and PL407-PL403) at room temperature $\left(25^{\circ} \mathrm{C}\right)$ and body temperature $\left(37^{\circ} \mathrm{C}\right)$. Even those PL systems did not form hydrogels (at $4 \% \mathrm{w} / \mathrm{w}$ ) the analysis was important to simulate the micelles behavior, when in contact with the physiological temperature, after hydrogels dissolution $[19,20]$.

At $25^{\circ} \mathrm{C}$, PL 407 and PL407-PL403 systems presented similar micellar diameters $(52.9 \pm 0.8$ and $52.0 \pm 2.0$, respectively), both also revealed a small size population $(\sim 5 \mathrm{~nm}$, with of $12.6 \pm 0.7$ and $9.0 \pm 0.6 \%$, respectively), related to the presence of unimers in solution [21-24].

The presence of HP- $\beta-C D$ increased the mean hydrodynamic diameter for both systems, reaching $62.6 \pm 3.8$ (PL407) and $54.3 \pm 2.2$ (PL407-PL403). In addition, an increment on micelle diameter was also observed in the presence of BUD. The presence of BUD:HP- $\beta-C D$ inclusion complex, resulted in large particles with diameters of $95.0 \pm 8.1$ (PL 407) and 59.0 \pm 2.5 (PL407/PL403), in relation to HP- $\beta$-CD or BUD-PL407 systems. All systems presented a bimodal distribution, with a polydispersity index between 0.35 and 0.53 , at $25^{\circ} \mathrm{C}$. The PL407-PL403 mixed micelles presented a smaller hydrodynamic diameter when compared to PL407 micelles at $25^{\circ} \mathrm{C}$, possibly due to the PL403 lower molecular weight $(\mathrm{MW}=5800)$ and hydrophobicity (HLB $=8)$.

On the other hand, at $37^{\circ} \mathrm{C}$, micellar hydrodynamic diameter presented dimensions between 22 and $35 \mathrm{~nm}$ with average distribution from 95 to $100 \%$ and polydispersity values of $0.17-0.22$ (revealing the predominance of an unimodal system), for all systems (Table 2), possibly due to the dehydration of PPO units, increasing the viscosity of the system $[25,26]$.

Our results suggest an interaction between HP- $\beta-C D$ and the PL PPO blocks [17] and the reorganization of the system as a result of BUD insertion into the micellar hydrophobic core $[27,28]$. In addition, an increase on micellar hydrodynamic diameter occurs not only because of the disposition of the hydrophobic molecule into the micellar core, but is also dependent on the aggregation number, since there is a raise on number of surfactant molecules per micelle that occurs in an attempt to cover up, or compensate for, the dilated core by the presence of the drug [28].

\subsection{Differential scanning calorimetry (DSC): micellization and thermal reversibility}

Thermal analysis was performed to study the micellization temperatures ( $T_{\text {onset }}, T_{\mathrm{m}}$ and $T_{\text {endset }}$ for the initial, peak and final micellization temperatures, respectively) for PL 407 or PL407-
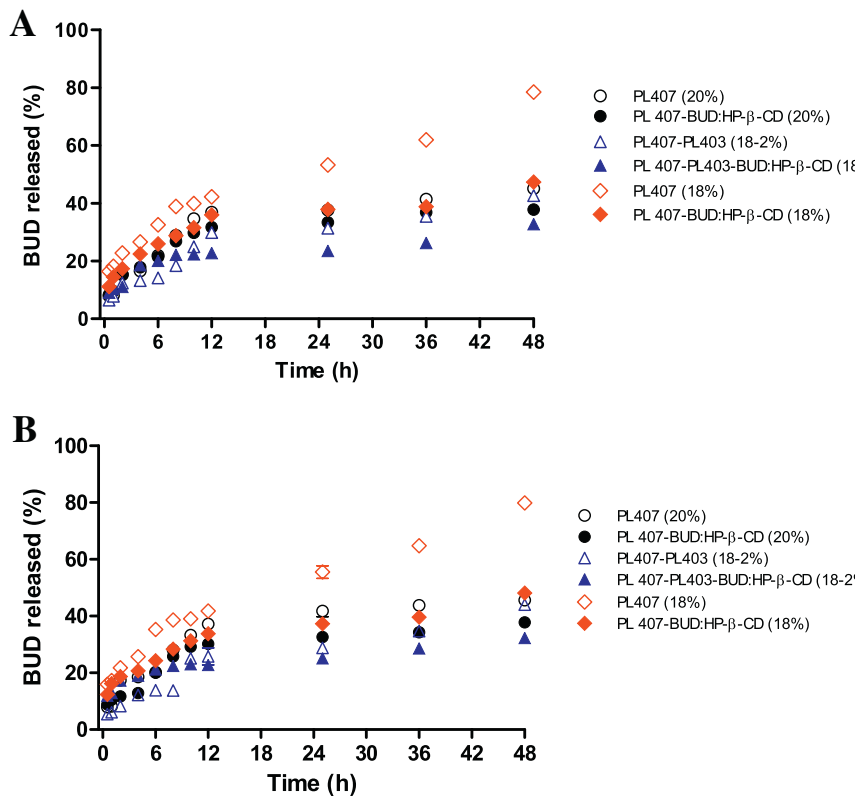

Fig. 4. In vitro release profiles for BUD from PL 407 and PL 407-PL403 hydrogels before and after BUD:HP- $\beta-C D$ inclusion complex incorporation ( $n=6 /$ formulation). (A) Simulated upper colon fluid (SUCF. pH 6.2) and (B) simulated lower colon fluid (SLCF. pH 7.0) ( $n=$ /formulation).

PL403 hydrogels and the influence of the BUD, HP- $\beta-C D$ and BUD:HP- $\beta-C D$ incorporation into the formulations (Table 3 ). Thermodynamic parameters were also determined, such as enthalpy variation $\left(\Delta H^{\circ}\right.$-area under the phase transition peak of the heating cycle), the Gibbs free energy variation $\left(\Delta G^{\circ}\right)$ and the entropy variation $\left(\Delta S^{\circ}\right)[21,29]$, according to Eqs. (5) and (6):

$\Delta G^{\circ}=R \times T_{\mathrm{CMT}} \times \ln (x)$
$\Delta G^{\circ}=\Delta H^{\circ}-T \times \Delta S^{\circ}$

where $R$ is the universal gas constant $\left(R=8.31 \mathrm{~J} \mathrm{~mol}^{-1} \mathrm{~K}^{-1}\right), T_{\mathrm{CMT}}$ is the critical micellization temperature (in Kelvin) and $x$ refers to the polymer concentration in units of mole fraction (considering $1 \mathrm{~g}$ sample).

For all formulations, the temperature range ( $\left.\Delta T=T_{\text {endset }}-T_{\text {onset }}\right)$ was calculated and variations were from $12.5^{\circ} \mathrm{C}$ (pure systems) to $17^{\circ} \mathrm{C}$ (after inclusion complex incorporation), showing that the addition of BUD-HP- $\beta-C D$ (1:1 molar ratio) changed the micellization temperatures. Regarding $T_{\text {onset }}$ and $T_{\mathrm{m}}$, no significant changes were observed among the formulations. However, the system $18 \%$ PL407-HP- $\beta$-CD presented higher temperatures, indicating that the incorporation of HP- $\beta-C D$ resulted on high enthalpy variation $\left(\Delta H^{\circ}=387.2 \mathrm{~kJ} \mathrm{~mol}^{-1}\right)$ value, possibly due to the interaction between PL and HP- $\beta-C D$, since PL unimers can remain free to selfassemble in micellar structures and additional energy is required for micellization. For the PL407 systems, an increase in the copolymer concentration decreased the value of $\Delta H^{\circ}$ in all formulations, suggesting that, in the presence of a greater number of monomers, the amount of energy required for the dehydration of the hydrophobic block of the PL is decreased and micellization enthalpy is proportional to PL concentration [30]. For PL407-PL403 formulation a decrease on enthalpy variation was observed, possibly related to the presence of a hydrophobic copolymer with lower molecular weight (PL403, MM = 5800) [31].

In the presence of BUD or HP- $\beta-C D$, an increase on enthalpy was observed for all formulations. However, after incorporation of BUD:HP- $\beta-C D$ (1:1 molar ratio) inclusion complex, a significant decrease on $\Delta H^{\circ}$ value occurred for $20 \%$ PL407 and 18-2\% PL407PL403, indicating that the complexation of BUD with HP- $\beta-C D$ did 
not modify the thermodynamics parameters for micelles formation. All systems presented a positive enthalpy variation $\left(\Delta H^{\circ}\right)$, showing an endothermic process as a result of the dehydration of the PPO blocks. Gibbs free energy variation $\left(\Delta G^{\circ}\right)$ values were negative, emphasizing that thermodynamically stable PL micelles are formed spontaneously in aqueous medium. The entropy variation $\left(\Delta S^{\circ}\right)$ is therefore positive and had a magnitude capable of compensating the enthalpy changes, making the process spontaneous $\left(\Delta G^{\circ}<0\right)$ (Table 3), in agreement with previous reports [21,29-33].

\subsection{Sol-gel phase transition temperature}

Table 3 shows the sol-gel transition temperatures for PL 407 or PL407-PL403 hydrogels in the presence or absence of BUD, HP$\beta-C D$ and BUD:HP- $\beta-C D$ inclusion complex. The formulations $20 \%$ PL407 and 18--2\% PL407-PL403, both with BUD or BUD:HP- $\beta$ $\mathrm{CD}$, presented $T_{\text {sol-gel }}$ values close to $35^{\circ} \mathrm{C}$ within an interesting temperature limit for pharmaceutical applications. Specifically for ulcerative colitis, this would enable the administration of those formulations by intra-colonic route in liquid form, but once in contact with the colon, they would form a hydrogel and adhere to the inflamed region.

For $20 \%$ PL407 with HP- $\beta-C D$, an increase on $T_{\text {sol-gel }}$ was observed, since the presence of HP- $\beta-C D$ can interfere on the formation of the micellar network due to the of hydroxyl groups $(-\mathrm{OH})$ that compete with the PEO units for the formation of hydrogen bonds, requiring high temperatures for the micelle-micelle assembling. Besides, previous studies reported an interaction between PPO units from PL407 and the hydrophobic cavity of HP- $\beta-C D$, forming supramolecular polypseudorotaxan complexes [34-39]. Comparisons between the formulations 18\% PL407 and 18-2\% PL407-PL403 (plain hydrogels) showed that PL403 did not shift the $T_{\text {sol-gel }}$. However, in the presence of BUD, HP- $\beta-C D$ or BUD:HP- $\beta$ $C D$, the association with PL403 favored the gelation close to the physiological temperature, allowing the use of lower concentrations of PL 407.

The addition of BUD to the formulations at 20\% PL 407 decreased the $T_{\text {sol-gel, }}$ as also observed by previous studies, where the addition of naproxen or indomethacin to the PL407 hydrogels shifted the gel-liquid limits to lower temperatures, indicating that the incorporation of drugs promotes the dehydration of PPO units and the aggregation of micelles, lowering the minimum critical gelation concentration (CGC) and minimum sol-gel transition temperature ( $\left.T_{\text {sol-gel }}\right)$ for hydrogel formation [39-41]. In addition, changes on $T_{\text {sol-gel }}$ were more expressive for the binary system PL407-PL403, enabling gelation close to body temperature due to the presence of more hydrophobic polymers (low PEO:PPO ratio), such as PL403. Although no systems based on 18\% PL407 formed a hydrogel until $37^{\circ} \mathrm{C}$, all of them proved to be systems in a soft gel or liquid-viscous state at lower body temperature. Considering that the commercial formulations containing BUD are administered in enema form (containing the drug in suspension), there is a greater formulation loss after application, due to the low formulation viscosity, which should not be expected for the hydrogels systems [42].

\subsection{FTIR analysis}

Fig. 2 presents the FTIR analysis for PL 407 isolated or its binary system with PL 403. The spectra relating to 18 and 20\% PL 407 and $18-2 \%$ PL407-PL403 showed absorption bands at $3000-2850 \mathrm{~cm}^{-1}$, $-\mathrm{CH}_{2}$ stretch was inherent to the bonds present in PEO and PPO blocks and the stretching vibration of $\mathrm{C}-\mathrm{C}$ bonds at $1100 \mathrm{~cm}^{-1}$ and at $1380 \mathrm{~cm}^{-1}$ due to the symmetric angular deformation of $\mathrm{CH}_{3}$ $[43,44]$.

The formation of the binary system between PL403 and PL407 increased the height of the pure PL407 possibly due to the pres- ence of PL403, amending the self-assembly of PL407 and indicating that the spectra presented significant changes due to the variation of PPO/PEO ratio, showing that the spectrum for PL403 resembles that obtained for a homopolymer composed of PPO because of its lipophilic structural features [45].

The infrared spectra for the systems containing BUD or HP- $\beta-C D$ (Fig. 2) shows that the drug or the inclusion complex incorporation increased the intensity of the bands identified in the spectra of pure compounds [46]. The addition of BUD or BUD-HP- $\beta-C D$ suggests a clutter in the polymer chains and the formation of a new arrangement, as a result of interaction between the drug or inclusion complex and PL. In addition, it was observed the appearance of a new band in the presence of BUD or BUD-HP- $\beta-C D$ inclusion complex, when compared to the pure PL407 or PL407-PL403, indicated the intermolecular interactions among the formulation components.

Moreover, it was also observed that the system PL 407 (20\%) HP$\beta-C D$ showed a reduction in the intensity of the bands, differently from that occurred after BUD or BUD: HP- $\beta-C D$ incorporation. This finding suggests the interaction of the HP- $\beta-C D$ with the copolymer in the absence of the drug, so that the PL vibrations are restricted. In fact, confirming $\mathrm{H}^{-1} \mathrm{NMR}$ data and considering the high value of the association constant BUD:HP- $\beta-\mathrm{CD}\left(\mathrm{Kc}=8662.8 \mathrm{M}^{-1}\right)$, can be inferred that the PL407 interacts with the hydrophobic cavity HP- $\beta$ CD only in the absence of BUD, but not when the inclusion complex BUD:HP- $\beta-C D$ is incorporated.

\subsection{Scanning electron microscopy (SEM): morphological analysis}

PL-based systems a predominance of layered or sheet structuring can be observed. Even after BUD, HP- $\beta-C D$ or BUD:HP- $\beta-C D$ incorporation into the formulations composed of PL407 and PL407/PL403 it is not possible to separate or identify each compound, which shows that those substances were effectively incorporated into the hydrogels (Fig. 3). It should be highlighted that similar patterns were observed when the inclusion complex was added to the hydrogels, as also observed by other authors [47].

\subsection{In vitro release studies}

Fig. 4(A and B) showed the results from the release profiles for hydrogels containing BUD or BUD-HP- $\beta-C D$ inclusion complex. In general, the BUD release percentage values from hydrogels composed of $18 \%$ PL 407 were higher compared to $20 \%$ PL 407 or $18-2 \%$ PL407-PL403 binary system, showing an influence of the PL concentration on release rate of BUD for both media. Other important point was that the hydrogels contained BUD-HP- $\beta-C D$ inclusion complex presented lower BUD release percentages, indicating that the complexation with HP- $\beta-C D$ prolonged the BUD release and it was not influenced by the presence of PL.

Differences were observed in terms of BUD released percentages, at $48 \mathrm{~h}$, for $18 \%$ PL 407 ( $47.3 \pm 0.7 \%), 20 \%$ PL F-127 (37.7 $\pm 0.3 \%)$ and $18-2 \%$ PL407-PL403 ( $32.8 \pm 0.3)$, containing BUD-HP- $\beta-C D$ inclusion complex, in comparison to $18 \%$ PL 407-BUD ( $78.5 \pm 0.5 \%)$ $(p<0.001)$. Even considering differences on PPO:PEO ratio between PL407 ( 1:3) and PL403 ( 2:1), the presence of PL403 was not able to displace the BUD from the HP- $\beta-C D$ cavity and/or induce its release from the hydrogels.

The BUD release kinetic constant values were determined considering zero order, Higuchi, Hixson-Crowell and Korsmeyer-Peppas mathematical models. For the systems composed of PL 407, the best fit was found to be the Higuchi model $\left(0.964 \leq R^{2} \leq 0.986\right)$, indicating the drug transport by diffusion according to the Fick's law [48], for both colonic fluids (Table 4), as also observed for PL 407 after incorporation of different drugs such as tramadol [20], lidocaine [49] and sumatriptan [19]. 
Regarding to the association PL407-PL403, the release profiles were better described by Korsmeyer-Peppas model $\left(R^{2} \geq 0.973\right)$ with release exponent lower than $0.5(n \sim 0.08)$, showing that even in the binary system, the BUD release mechanism is controlled by diffusion and follows thereafter the Higuchi model $\left(R^{2} \geq 0.937\right)$. For the systems containing inclusion complex, the BUD release is still determined by Fickian diffusion as proposed by Higuchi model $\left(R^{2}=0.914\right)$. However, it is observed that the release profile also follows the Hixson-Crowell model $\left(R^{2}=0.913\right)$, suggesting that the release is limited by the drug dissolution rate and not only by diffusion, which can occur through the polymeric matrix [50,51]. For poorly soluble drugs, such as corticosteroids, the release is also controlled by hydrogel erosion due to water penetration into the polymeric matrix and hydration of the polymer chains [52,53].

\section{Conclusions and perspectives}

In this work, we proposed the improvement of BUD physicochemical properties through complexation with HP- $\beta-C D$ and the incorporation of its inclusion complex into PL-based hydrogels, aiming the construction of self-assembled supramolecular stimuliresponsive architectures. Considering the CD-PL interactions and also their interference on the maintenance of the drug-CD inclusion complexes or the possible drug displacement from de CD cavity into the hydrogels systems, the physicochemical aspects regarding the incorporation of BUD-HP- $\beta$-CD into PL407 or PL407-PL403 systems were studied.

The complexation with HP- $\beta-C D$ associated to the incorporation in PL407 or PL407-PL403 systems improved the BUD solubility in simulated colon fluids. The ability of CDs for complexing drug molecules, can lead a dual role in the presence of copolymers, such as PL, including: (i) the increase on aqueous solubility of hydrophobic drugs in the presence of PL and HP- $\beta-C D$ (compared to the isolated systems) and (ii) a competition mechanism between PL and drugs for complexation with the $\mathrm{CD}$ hydrophobic cavity, forming the polypseudorotaxane complexes $[53,54]$. In this context, our results showed that for BUD:HP- $\beta-C D$ there is no influence of drug-PL competition for the HP- $\beta-C D$ cavity. Our results showed an interaction between HP- $\beta-C D$ and the PL, including the reorganization of the system as a result of BUD insertion into the micellar hydrophobic core. Besides, the HP- $\beta-C D$ insertion into the PL 407 system increased the $\Delta H^{\circ}$ value, but did not shift the $T_{\text {sol-gel }}$ temperature value. The HP- $\beta-C D$, BUD or BUD-HP- $\beta-C D$ incorporation into PL407-PL403 reduced the $T_{\text {sol-gel }}$ and the association of PL407 with a PL403 favored the gelation and the self-assembly micelle-micelle network.

In spite of the interaction between the PL407 and the hydrophobic cavity of HP- $\beta-C D$, PL407 or PL 407-PL403 systems were not capable to displace BUD from the HP- $\beta-C D$ cavity, showing that the drug partitioning and the high association constant drug: $C D$ $\left(\mathrm{Kc}=8662.8 \mathrm{M}^{-1}\right.$, BUD-HP- $\left.\beta-\mathrm{CD}\right)$ can modulate the interaction between PL and CD, since PL407 or PL407-PL403 interacted with the hydrophobic cavity HP- $\beta-C D$ only in the absence of BUD, highlighting the interest for the development of new pharmaceutical formulation associating those carriers.

For hydrophobic drugs, CDs can influence the release rate and increase the drug partitioning into the hydrogel matrix, since the hydrogel matrix reduces the possibility of fast dissolution of the inclusion complex, when in contact with physiological fluids. Although the inclusion complexes are incorporated, the equilibrium between the formation of polyrotaxanes and the maintenance of the inclusion complex into the hydrogel matrix depends on the drug-CD association constant, possibly affecting the ability of $C D$ molecules to interact with the polymeric network [54,55]. In general, the BUD release mechanism occurs predominantly by drug diffusion process through the polymeric matrix, following Fick's law. Finally, these promising findings point out the system BUDHP- $\beta-C D$ in PL-based hydrogels as strategies for future in vivo investigations and also the development of new pharmaceutical formulations looking forward the treatment of ulcerative colitis.

\section{Acknowledgments}

This work was supported by Coordenação de Aperfeiçoamento de Pessoal de Nível Superior (CAPES), Fundação de Amparo à Pesquisa do Estado de São Paulo (FAPESP 2014/26200-9, 2014/14457-5) and Conselho Nacional de Desenvolvimento Científico e Tecnológico (CNPq 487619/2012-9, 309612/2013-6).

\section{Appendix A. Supplementary data}

Supplementary data associated with this article can be found, in the online version, at http://dx.doi.org/10.1016/j.colsurfb.2015.11. 048 .

\section{References}

[1] R.N. Baldassano, D.A. Piccoli, Gastroenterol. Clin. North Am. 28 (1999) 445-458.

[2] J. Varshosaz, J. Emami, A. Fassihi, N. Tavakoli, M. Minaiyan, F. Ahmadi, P. Mahzouni, P. Dorkoosh, Int. J. Colorectal Dis. 25 (2010) 1159-1165.

[3] F.L. Mota, A.P. Carneiro, A.J. Queimada, S.P. Pinho, E.A. Macedo, Eur. J. Pharm. Sci. 37 (2009) 499-507.

[4] A.S. Johansson, K.E. Anderson, R. Brattsand, E. Gruvstad, P. Hedner, Eur. J. Clin. Pharmacol. 22 (1982) 523-529.

[5] T. Loftsson, M. Masson, Int. J. Pharm. 225 (2001) 15-30.

[6] T. Loftsson, D. Duchêne, Int. J. Pharm. 329 (2007) 1-11.

[7] F.L. Guedes, G.M.C. Alves, F.L.A. Santos, L.F. Lima, L.A. Rolim, P.J.R. Neto, Rev, Bras. Farm. 89 (2008) 220-225.

[8] D.A. Chiappetta, A. Sosnik, Eur. J. Pharm. Biopharm. 66 (2007) 303-317.

[9] H. Wen, K. Park, New Jersey: John Wiley \& Sons (2010) 47-70.

[10] I.R. Schmolka, J. Biomed. Mater. Res. 6 (1972) 571-582.

[11] H. Yang, Y. Zheng, B. Zhao, T. Shao, Q. Shi, N. Zhou, W. Cai, Biomaterials 38 (2013) 9770-9778.

[12] S.S. Kulthe, N.N. Inamdar, Y.M. Choudhari, S.M. Shirolikar, L.C. Borde, V.K. Mourya, Colloids Surf. B: Biointerfaces 88 (2011) 691-696.

[13] V. Saxena, M.D. Hussain, Int. J. Nanomed. 7 (2012) 713-721.

[14] S. Alexander, T. Cosgrove, T.C. Castle, I. Grillo, S.W. Prescott, J. Phys. Chem. B. 116 (2012) 11545-11551.

[15] L. Nogueiras-Nieto, E. Sobarzo-Sánchez, J.L. Gómez-Amoza, F.J. Otero-Espinar, Eur. J. Pharm. Biopharm. 80 (2012) 585-595

[16] Y.A. Mondjinou, L.A. Mccauliff, A. Kulkarni, L. Paul, S.H. Hyun, Z. Zhang, Z. Wu, M. Wirth, J. Storch, D.H. Thompson, Biomacromolecules 14 (2013) 4189-4197.

[17] J. Qin, X. Meng, B. Li, W. Ha, X. Yu, S. Zhang, J. Colloid Interface Sci. 350 (2010) $447-452$.

[18] C.J. Collins, L.A. Mccauliff, S.H. Hyun, Z. Zhang, L.N. Paul, A. Kulkarni, K. Zick, M Wirth, J. Storch, D.H. Thompson, Biochemistry 52 (2013) 3242-3253.

[19] A. Oshiro, D.C. da Silva, J.C. de Mello, V.W.R. de Moraes, L.P. Cavalcanti, M.K.K.D. Franco, M.I. Alkschbirs, L.F. Fraceto, F. Yokaichiya, T. Rodrigues, D.R. de Araujo, Langmuir 30 (2014) 13689-13698.

[20] A.C.M. Santos, A.C.S. Akkari, I.R.S. Ferreira, C.R. Maruyama, M. Pascoli, V.A. Guilherme, E. de Paula, L.F. Fraceto, R. Lima, P.S. Mello, D.R. de Araujo, Int. J. Nanomed. 10 (2015) 2391-2401.

[21] P. Alexandridis, T. Hatton, Colloids Surf. A: Physicochem. Eng. Aspects 96 (1995) $1-46$

[22] P.R. Desai, N.J. Jain, R.K. Sharma, P. Bahadur, Colloids Surf. A 178 (2001) 57-69.

[23] L. Gentile, G. De Luca, F.E. Antunes, C.O. Rossi, G.A. Ranieri, Appl. Rheol. 20 (2010) 52018

[24] C. Pradal, K.S. Jack, L. Grondahl, J.J. Cooper-White, Biomacromolecules 14 (2013) 3780-3792

[25] K. Nakashima, P. Bahadur, Adv. Colloid Interface Sci. 216 (2006) 75-96.

[26] A. Parmar, K. Singh, A. Bahadur, G. Marangoni, P. Bahadur, Colloids Surf. B: Biointerfaces 86 (2011) 319-326.

[27] C. He, S.W. Kim, D.S. Lee, J. Control. Release 127 (2008) 189-207.

[28] M. Valero, C.A. Dreiss, Langmuir 26 (2010) 10561-10571.

[29] R. Basak, R. Bandyopadhyay, Langmuir 29 (2013) 4350-4356.

[30] J. Ma, C. Guo, Y. Tang, J. Xiang, S. Chen, J. Wang, H. Liu, J. Colloid Interface Sci. 312 (2007) 390-396.

[31] L.C. Trong, M. Djabourov, A. Ponton, J. Colloid Interface Sci. 328 (2008) $278-287$.

[32] H.W. Tsui, J.H. Wang, Y.H. Hsu, L.J. Chen, Colloid Polym. Sci. 288 (2010) 1687-1696.

[33] D.A. Chiappetta, A. Sosnik, Eur. J. Pharm. Biopharm. 66 (2007) 303-317.

[34] T. Ur-Rehman, S. Tavelin, G. Gröbner, Int. J. Pharm. 394 (2010) 92-98. 
[35] N. Zeng, G. Dumortier, M. Maury, N. Mignet, V. Boudy, Int. J. Pharm. 467 (2014) 70-83.

[36] L. Nogueiras-Nieto, C. Alvarez-Lorenzo, I. Sandez-Macho, A. Concheiro, F.J. Otero-Espinar. J. Phys, Chem. B 113 (2009) 2773-2782.

[37] E. Bílková, M. Sedlák, B. Dvořák, K. Ventura, P. Knotek, L. Beneš, Org. Biomol. Chem. 23 (2010) 5423-5430.

[38] L. García-Río, F.J. Otero-Espinar, A. Luzardo-Alvarez, J. Blanco-Méndez, Curr. Top. Med. Chem. 14 (2014) 478-493.

[39] G. Bonacucina, M. Spina, M. Misici-falzi, M. Cespi, S. Pucciarelli, M. Angeletti, G.F. Palmieri, Eur. J. Pharm. Sci. 32 (2007) 115-122

[40] P.K. Sharma, M.J. Reilly, S.K. Bhatia, N. Sakhitab, J.D. Archambult, S.R. Bhatia, Colloid Surf. B: Biointerfaces 63 (2008) 229-235.

[41] B. Jeong, S.W. Kim, Y.H. Bae, Adv. Drug Deliv. Rev. 54 (2002) 37-51.

[42] E. Larran eta, J.R. Isasi, Langmuir 29 (2013) 1045-1053.

[43] H.R. Lin, P.C. Chang, J. Biomed. Mater. Res. B: Appl. Biomater. 101 (2013) 689-699.

[44] C. Guo, H. Liu, J. Wang, J. Chen, J. Colloid Interface Sci. 209 (1999) 368-373.
[45] D.A. Alvares, J.C. Moreira, C.H. Scuracchio, R.K. Onmori, Macromol. Symp. 245 (2007) 343-346.

[46] C.C. Chen, C.L. Fang, S.A. Al-Suwayeh, Y.L. Leu, J.Y. Fang, Int. J. Pharm. 415 (2011) 119-128.

[47] Md. Asaduzzaman, Md. R. Rahman, Md. S.R. Khan, S.M.A. Islam, J. Appl. Pharm. Sci. 8 (2011) 131-136.

[48] P. Costa, J.M.S. Lobo, Eur. J. Pharm. Sci. 13 (2001) 123-133.

[49] E.J. Ricci, L.O. Lunardi, D.M. Nanclares, J.M. Marchetti, Int. J. Pharm. 288 (2005) 235-244.

[50] D.M. Morkhade, V.S. Nande, U.V. Barabde, A.T. Patil, S.B. Joshi, AAPS PharmSciTech 8 (2007) 134-142.

[51] R. Machiín, J.R. Isasi, I. Veílaz, Eur. Polym. J 49 (2013) 3912-3920.

[52] P. Kumar, I. Singh, Acta Pol. Pharm. 67 (2010) 307-313.

[53] M. Valero, C.A. Dreiss, J. Phys.: Conf. Sci. 549 (2014) 1-5.

[54] G. Bonacucina, M. Spina, M. Misici-Falzi, M. Cespi, S. Pucciarelli, M. Angeletti, G.F. Palmieri, Eur. J. Pharm. Sci. 32 (2007) 115-122.

[55] S. Daoud-Mahammed, J.L. Grossiord, T. Bergua, C. Amiel, P. Couvreur, R. Gref, J. Biomed. Mater. Res. A. 86 (2008) 736-748. 